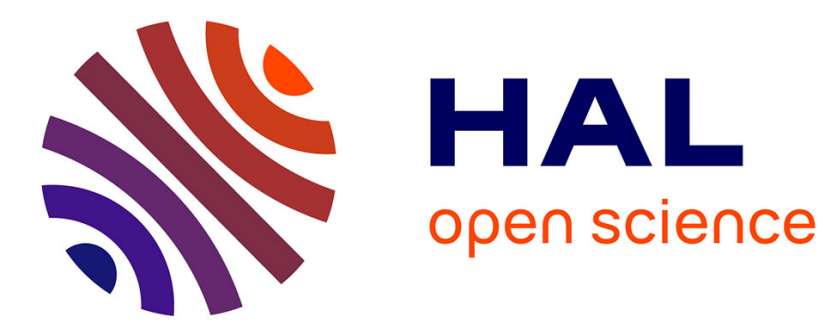

\title{
Cardiorespiratory Responses to Continuous and Intermittent Exercises in Children
}

Georges Baquet, Francois-Xavier Gamelin, Julien Aucouturier, Serge Berthoin

\section{To cite this version:}

Georges Baquet, Francois-Xavier Gamelin, Julien Aucouturier, Serge Berthoin. Cardiorespiratory Responses to Continuous and Intermittent Exercises in Children. International Journal of Sports Medicine, 2017, International journal of sports medicine, 38 (10), pp.755-762. 10.1055/s-0043-111892 . hal-02375510

\section{HAL Id: hal-02375510 https://hal.univ-lille.fr/hal-02375510}

Submitted on 12 May 2020

HAL is a multi-disciplinary open access archive for the deposit and dissemination of scientific research documents, whether they are published or not. The documents may come from teaching and research institutions in France or abroad, or from public or private research centers.
L'archive ouverte pluridisciplinaire HAL, est destinée au dépôt et à la diffusion de documents scientifiques de niveau recherche, publiés ou non, émanant des établissements d'enseignement et de recherche français ou étrangers, des laboratoires publics ou privés. 


\section{Baquet G, Gamelin FX, Aucouturier J, Berthoin S.}

Cardiorespiratory Responses to Continuous and Intermittent Exercises in Children.

Int J Sports Med. 2017 Sep;38(10):755-762

\section{doi: $10.1055 / \mathrm{s}-0043-111892$}

\section{PMID: 28783846Abstract}

The aim of the present study was to characterize aerobic responses to HIIE and CE in prepubertal children. Twenty-five 8 to 11 -year-old children took part to a preliminary visit to determine peakVO $\mathrm{V}_{2}$ and Maximal Aerobic Velocity (MAV). During the 5-following experimental visits, the participants completed $2 \mathrm{CE}$ and 3 HIIE sessions in a randomized order. The HIIE consisted of short intermittent 10 and 20-s running bouts from 100 to $130 \%$ of MAV, interspersed with recovery periods of equal duration (S-HIIE1 and S-HIIE2 respectively) and 5-s sprinting and jumping at maximal intensity with 15 -s recovery periods (S-HIIE3). Continuous submaximal exercises consisted of two 10 -min running periods at $80 \%$ and $85 \%$ of MAV with a 5-min recovery period. CE protocols elicited higher average $\mathrm{VO}_{2}$ and exercise time spent above $95 \%$ of peakVO 2 than HIIE protocols. S-HIIE 1 and S-HIIE 2 elicited similar average $\mathrm{VO}_{2}$ response and higher than S-HIIE 3. Our study has shown that $\mathrm{CE}$ activated the aerobic system to a greater extent than S-HIIE in prepubertal children, as reflected by exercise time above $95 \%$ of peakVO . However, isotime S-HIIE protocols of either 10 or 20 -s exercise bouts at an intensity above MAV result to similar exercise times at high oxygen consumption rates ( above 95\% $\mathrm{VO}_{2}$ peak).

Keywords: Oxygen uptake, Exercise modalities, Maximal Aerobic Velocity, Children. 


\section{Introduction}

The manipulation of exercise intensity, duration, and of work and recovery periods characteristics during High Intensity Intermittent Exercise (HIIE) determines the amount of time spent at exercise intensity close to peak oxygen uptake $\left(\mathrm{VO}_{2 \text { peak }}\right)$. The accumulation of time near $\mathrm{VO}_{2 \text { peak }}$ over repeated exercise sessions is recognized as an important factor contributing to the gain in aerobic capacity in response to exercise training [20]. There is growing evidence that both continuous submaximal intensity exercise (CE) and HIIE training protocols are effective in improving peakVO 2 in children $[2,9,11]$, which raise the question of the relative efficacy of these two modalities of exercise training.

Over a single exercise session, the physiological stress is often quantified by the amount of time spent above various threshold, ranging from $80 \%$ to $95 \%$ of $\mathrm{VO}_{2 \max }[23,28,30]$. HIIE typically consists of exercise bouts at intensity of at least $90 \%$ peakVO $\mathrm{V}_{2}$ interspersed with periods of passive or active recovery [5]. HIIE with short duration work and recovery periods (S-HIIE) at intensity $\geq 100 \% \mathrm{VO}_{2 \max }$ is especially used in children, and is effective to improve $\mathrm{VO}_{2 \max }[3]$. During CE, Baquet et al. [2] previously indicated in a review that the exercise intensity needs to be above $80 \%$ of maximal heart rate to elicit significant improvement of $\mathrm{VO}_{2 \max }$ in children and adolescents. Adolescents were then showed to spend more time above $80 \% \mathrm{VO}_{2 \max }$ during heavy intensity continuous exercise relative to 30 -s HIIE protocol performed at $110 \%$ of MAV conducted to exhaustion, which provides support for $\mathrm{CE}$ as an effective exercise modality to strongly activate the cardiorespiratory system [30]. However, adolescents have to exercise for 1.5 to 2 times longer during CE than during S-HIIE to elicit such responses [30]. Although young endurance athletes can perform such exercise to exhaustion to maximize physiological stress during training sessions, the amount of time devoted to aerobic conditioning is limited in many team sports or during PE classes. Moreover, when the accumulated exercise time at near maximal aerobic system activation $\left(95 \% \mathrm{VO}_{2 \max }\right)$ was examined, the 30 -s HIIE protocol was 
equally effective to $\mathrm{CE}$ to activate the cardiorespiratory system, despite shorter time to exhaustion [30]. It is therefore important to determine which exercise modalities elicit the largest amount of time at a high percentage of $\mathrm{VO}_{2 \max }$ over exercise duration typically shorter than 30 minutes. In this regard, Nicolò et al. [20] have reported that overall effort and total duration of exercise are two critical parameters that should both be controlled when comparing continuous and intermittent exercise modalities.

The purpose of the present study was therefore to determine the exercise modality that elicited the greatest cardiorespiratory system activation among 3 S-HIIE differing for exercise and recovery durations at intensity $\geq 100 \%$ MAS and 2 modalities of CE at intensity $\geq 80 \%$ MAS matched for total duration in 8-11year-old prepubertal children. The time spent above 95\% $\mathrm{VO}_{2 \max }$ was used as the primary outcome, and average $\mathrm{VO}_{2}$ and Heart Rate were used as secondary outcomes. We hypothesized that S-HIIE with the longest duration work periods would result in higher cardiorespiratory system activation relative to CE and S-HIIE with shorter work period duration.

\section{Methods}

\section{Experimental approach to the problem}

\section{Subjects}

Twenty-five 8 to 11 - year-old children (12 boys and 15 girls) participated in the study. The children's parents signed a written informed consent after being fully informed for possible risks and discomforts associated with the exercise protocols and testing procedures of the study. The study was designed in accordance with the ethical standards of the Helsinki Declaration of 2013, received the approval of the local "Consultative Committee for the Protection of Persons in Biomedical Research" and met the ethical standards of the IJSM [13]. Stature and body mass were measured with a wall stadiometer (Vivioz Medical, Paris, France) and a calibrated beam 
balance (Tanita TBF 543, Tokyo, Japan), to the nearest $0.1 \mathrm{~cm}$ and $0.1 \mathrm{~kg}$, respectively. Percentage of body fat was estimated from skinfold thickness measured at three sites (biceps, triceps and calf; Harpenden skinfold caliper HSK-BI), according to Slaughter-Lohman equations [16]. Sexual maturity was assessed from pubertal stages: indices of breast, pubic hair and genital development [22]. All boys $(n=11)$ were at stage 1 for genital development and pubic hair. Thirteen girls were at stage 1 for breast and pubic hair, while for the remaining girls $(\mathrm{n}=2)$ the combined stage assessment was $\leq 3$.

\section{Experimental design}

Before entering the study, the children were familiarized with the exercise testing procedures. After a preliminary visit to determine peakVO $\mathrm{V}_{2}$ and Maximal Aerobic Velocity (MAV), the children took part to five experimental sessions conducted in a randomized order. They performed three S-HIIE with distinct work duration, exercise intensity and work-to-recovery duration ratio, and two CE. Each session lasted between 25 and 27 minutes. During the preliminary visit and each of S-HIIE and CE protocol, respiratory gas exchange values were measured breath-by-breath using a portable system (Cosmed K4b ${ }^{2}$, Rome, Italy) [17]. Before each test, the $\mathrm{O}_{2}$ and $\mathrm{CO}_{2}$ analyzers were calibrated using ambient air and a gas of known $\mathrm{O}_{2}$ $(16 \%)$ and $\mathrm{CO}_{2}(5 \%)$ concentrations. For the calibration of the turbine flowmeter of the $\mathrm{K} 4 \mathrm{~b}^{2}$, a 3-1 syringe (Quinton Instruments, Seattle, Wash., USA) was used. $\mathrm{VO}_{2}$ and $\mathrm{CO}_{2}$ values were averaged at $5 \mathrm{~s}$ periods. Heart rate (HR) was continuously monitored (Polar Accurex + , Polar Electro, Kempele, Finland).

For each exercise test, average $\mathrm{VO}_{2}$, average $\mathrm{HR}$, peakVO2, peakHR, peakVE, energy expenditure and time spent above $95 \%$ peakVO $2\left(\mathrm{t}_{95}\right.$ peakVO $\left.\mathrm{V}_{2}\right)$ were calculated [10].

\section{Peak oxygen uptake and Maximal Aerobic Velocity}

Before the five experimental visits, children underwent a maximal graded test on a treadmill, to determine peakVO 2 and $\mathrm{MAV}$. The children were familiarized with treadmill running before 
the start of the test. The test started with an initial velocity of $6 \mathrm{~km} \cdot \mathrm{h}^{-1}$, and the speed was then increased by $0.5 \mathrm{~km} \cdot \mathrm{h}^{-1}$ every 1 -min. The speed at the last completed stage was considered as the MAV [6]. PeakVO 2 was determined as the mean of the two highest $5 \mathrm{~s}_{2}$ values. Criteria for considering that peak $\mathrm{VO}_{2}$ had been reached were maximal heart rate (HRmax) above 195 bpm, respiratory exchange ratio (RER) above 1.00, associated with visible exhaustion [24]. PeakVO 2 , HRmax, RER and maximal Ventilation (VEmax) obtained for the graded test were, respectively, $54.9 \pm 6.8 \mathrm{ml} \cdot \mathrm{kg}^{-1} \cdot \mathrm{min}^{-1}, 215 \pm 7 \mathrm{bpm}, 1.02 \pm 0.06$ and $71.0 \pm 10.11 . \mathrm{min}^{-1}$. MAV was $11.7 \pm 1.1 \mathrm{~km} \cdot \mathrm{h}^{-1}$

\section{High Intensity Intermittent exercise}

S-HIIE1 consisted of short intermittent runs with work and recovery duration lasting 10sec/10-sec. The exercise session consisted of five sets of 10 repetitions interspersed with 3 min recovery between sets. Intensity increased by $10 \%$ of MAV at each set, from $100 \%$ of MAV during the $1^{\text {st }}$ set to $130 \%$ of MAV during the $5^{\text {th }}$ set. S-HIIE2 consisted of short intermittent runs with work and recovery duration lasting $20-\mathrm{sec} / 20$-sec. The exercise session consisted of five sets of 5 repetitions interspersed with 3 min recovery between sets. Intensity increased by $10 \%$ of MAV at each set, from $100 \%$ of MAV during the $1^{\text {st }}$ set to $130 \%$ of MAV during the $5^{\text {th }}$ set.

S-HIIE1 and S-HIIE2 were performed on a track. Each child had to cover the distance corresponding to $10 \mathrm{~s}$ (S-HIIE1) or 20s (S-HIIE2) at the required MAV. For example, a subject with a $9 \mathrm{~km} \cdot \mathrm{h}^{-1} \mathrm{MAV}$ had to run over $50 \mathrm{~m}$ in $20 \mathrm{~s}$, at $100 \%$ of MAV. After $20 \mathrm{~s}$ of recovery, the child turned back and repeated the run in the opposite direction. S-HIIE3 consisted of allout sprint running and jumping with exercise to recovery sequences lasting $5 \mathrm{~s}$ and $15 \mathrm{~s}$, respectively. For S-HIIE3, each child sprinted or performed maximal vertical jumps during $5 \mathrm{~s}$ interspersed with $15 \mathrm{~s}$ of recovery. Each child was continuously encouraged with an 
experimenter running next to him for each experimental session. Details of the experimental sessions are outlined in Table 1.

\section{Continuous Exercise}

CE sessions included two sets of 10 min with 5-min recovery between each set. Intensity was set at 80 (CE80) and $85 \%$ of MAV (CE85). CE were performed on a $250 \mathrm{~m}$ track marked with cones every $25 \mathrm{~m}$. Each child was continuously encouraged by an experimenter (using a timer) who ran next to him for each session. The timer emitted a brief sound that indicated to the children the moment they had to pass near a cone to maintain a constant speed. Details of the training sessions are outlined in Table 1.

\section{Statistical analysis}

The normality of the data distribution was checked using the Kolmogorov-Smirnov test. The experimental values were expressed as mean \pm standard deviation (mean $\pm \mathrm{SD}$ ). Data were analyzed using a one-way ANOVA (training session) with repeated measures. Bonferonni post hoc analyses were conducted to identify a difference between training sessions and training sets. Cohen's d corrected by Hopkins was calculated to determine the effect size (ES) that was assessed using the following criteria: $0 \leq \mathrm{ES} \leq 0.2=$ trivial, $0.2<\mathrm{ES} \leq 0.6=$ small, $0.6<\mathrm{ES} \leq$ $1.2=$ moderate, $1.2<\mathrm{ES} \leq 2.0=$ large, $2.0<\mathrm{ES} \leq 4.0=$ very large, $>4.0=$ nearly perfect [14] Data were analyzed with InStat (Graphpad Software Inc, La Jolla). The threshold for statistical significance was set at $\mathrm{p}<0.05$. 


\section{Results}

Cardiorespiratory responses and energy expenditure values attained during S-HIIE and CE sessions are reported in Table 2. Effect size and 95\% confidence intervals for average oxygen uptake $\left(\mathrm{VO}_{2}\right)$, average Heart Rate (HR) and $\mathrm{t}_{95}$ peakVO 2 between each session are reported in Table 3.

\section{Oxygen uptake}

Table 2 presents average $\mathrm{VO}_{2}$ and peakVO 2 during S-HIIE and $\mathrm{CE}$ sessions. Average $\mathrm{VO}_{2}$ $\left(\mathrm{ml} \cdot \mathrm{kg}^{-1} \cdot \mathrm{min}^{-1}\right)$ was significantly higher $(\mathrm{p}<0.001)$ in CE80 and CE85 than all three S-HIIE, and in S-HIIE1 $(p<0.05)$ and S-HIIE2 $(p<0.001)$ than in S-HIIE3. The attained peakVO $\mathrm{F}_{2}$ was similar between CE80, CE85, S-HIIE1 and S-HIIE2. The participants during S-HIIE3 attained a significantly lower peakVO 2 value than in CE85 $(p<0.01)$ and S-HIIE2 $(p<0.001)$ protocols. PeakVE values are reported in Table 2. The attained peakVE was similar in CE80, CE85, SHIIE1 and S-HIIE2 protocols; whereas it was significantly lower in S-HIIE3 than CE85 $(\mathrm{p}<0.01)$ and S-HIIE2 $(\mathrm{p}<0.001)($ Table 2$)$.

Table 3 shows the effect sizes and $95 \%$ confidence intervals for average $\mathrm{VO}_{2}$. Very large effects were found in average $\mathrm{VO}_{2}$ between CE80 and S-HIIE sessions (ES CE80 vs S-HIIE1 = 2.47, $95 \% \mathrm{CI}=1.72,3.22 ;$ ES CE80 vs S-HIIE2 $=2.34,95 \% \mathrm{CI}=1.57,3.03$; ES CE80 vs S-HIIE3 = $3.34,95 \% \mathrm{CI}=2.42,4.16$ ). Very large to nearly perfect effects were found in average $\mathrm{VO}_{2}$ between CE85 and S-HIIE (ES CE85 vs S-HIIE1 = 3.38, 95\%CI = 2.35, 4.27; ES CE85 vs SHIIE2 $=3.46,95 \% \mathrm{CI}=2.43,3.47$; ES CE85 vs S-HIIE3 $=4.24,95 \% \mathrm{CI}=3.05,4.25)$. Comparisons among S-HIIE protocols for average $\mathrm{VO}_{2}$ showed a moderate effect between SHIIE1 and S-HIIE3 $(\mathrm{ES}=0.95,95 \% \mathrm{CI}=0.33,1.53)$ and a large effect between S-HIIE2 and S-HIIE3 $(E S=1.61,95 \% \mathrm{CI}=0.96,2.27)$. Figure 1 shows the kinetics of oxygen uptake during S-HIIE1, S-HIIE2 and S-HIIE3 and CE85. The data were representative from the same subject $\boldsymbol{H R}$ 
Table 2 presents average HR and peakHR during S-HIIE and CE sessions. Average HR (bpm) was significantly higher $(\mathrm{p}<0.001)$ in CE80 and CE85 than S-HIIE sessions. No significant difference was found between S-HIIE sessions. PeakHR was similar between CE80, CE85, SHIIE1 and S-HIIE2. S-HIIE3 showed significantly lower peakHR than CE80 $(\mathrm{p}<0.05)$, CE85 and S-HIIE2 $(\mathrm{p}<0.001)$. Table 3 shows the effect size and 95\% confidence intervals for average HR between each session. Comparisons among protocols for average HR showed large effects between CE80 and HIIE (ES CE80 vs S-HIIE1 $=2.08,95 \% \mathrm{CI}=1.30,2.87$; ES CE80 vs SHIIE2 $=1.99,95 \% \mathrm{CI}=1.27,2.71 ; \mathrm{ES} \mathrm{CE} 80$ vs S-HIIE3 $=2.19,95 \% \mathrm{CI}=1.46,2.53)$ and very large effects between CE85 and S-HIIE (ES CE85 vs S-HIIE1 $=2.87,95 \% \mathrm{CI}=1.76,3.92 ; \mathrm{ES}$ CE85 vs S-HIIE2 $=3.10,95 \% \mathrm{CI}=2.02,4.18$; ES CE85 vs S-HIIE3 $=3.07,95 \% \mathrm{CI}=2.03$, 4.19).

\section{Time spent above $95 \%$ peakVO}

One child and four children did not reach $95 \%$ of peakVO 2 during S-HIIE1 and S-HIIE3 protocols, respectively. Table 2 presents t $_{95}$ peakVO $\mathrm{VO}_{2}$ during S-HIIE and CE sessions. Time spent above $95 \%$ peakVO 2 (s) was significantly higher in CE85 than S-HIIE sessions $(p<0.01)$, in CE80 than S-HIIE1 and HIIE3 $(\mathrm{p}<0.05)$ and in S-HIIE2 than S-HIIE3 $(\mathrm{p}<0.05)$. Table 3 depicts effect size and $95 \%$ confidence intervals of the effect between protocols for exercise time about $\mathrm{t} 95 \mathrm{VO}_{2}$ peak between each session. Large effects were found in $\mathrm{t}_{95}$ peak $\mathrm{VO}_{2}$ between CE85 and S-HIIE protocols (ES CE85 vs S-HIIE1 $=1.41,95 \% \mathrm{CI}=0.70,2.12$; ES CE85 vs SHIIE2 $=1.15,95 \% \mathrm{CI}=0.47,1.83$; ES CE85 vs S-HIIE3 $=1.78,95 \% \mathrm{CI}=1.04,2.53$ ). Moderate effects were showed in t95 $_{9}$ peakVO ${ }_{2}$ between CE80 and S-HIIE1 (ES CE80 vs S-HIIE1 $=0.72$, $95 \% \mathrm{CI}=0.12,1.31)$ and between CE80 and S-HIIE3 (ES CE80 vs S-HIIE3 $=1.07,95 \% \mathrm{CI}=$ $0.46,1.67)$. Regarding the difference between S-HIIE sessions, $\mathrm{t}_{95}$ peakVO 2 showed a moderate effect between S-HIIE2 than S-HIIE3 (ES=1.03, 95\%CI $=0.45,1.61 . \mathrm{p}<0.05)$. 


\section{Energy expenditure}

Energy expenditure values are reported in Table 2. Energy expenditure was significantly higher $(\mathrm{p}<0.001)$ during CE80 and CE85 (182.2 \pm 32.3 and $194.7 \pm 39.8 \mathrm{kcal}$, respectively) than during S-HIIE protocols. The total kcals consumed in S-HIIE1 and S-HIIE2 were significantly higher than during S-HIIE3 $(153 \pm 24.7$ and $160.9 \pm 26.3$ vs $127.5 \pm 22.5 \mathrm{kcal}$, respectively; $\mathrm{p}<0.001)$.

\section{Discussion}

This study was designed to characterize the activation of aerobic metabolism in response to different modalities of exercise commonly used to improve cardiorespiratory fitness in prepubertal children. The key findings of this study were two-fold. Firstly, CE protocols elicited higher average $\mathrm{VO}_{2}$ and time spent above $95 \%$ of $\mathrm{VO}_{2}$ max than S-HIIE protocols. Secondly, the aerobic system activation was lower in response to sprint running and jumping exercises interspersed with short recovery periods relative to the other S-HIIE or CE protocols.

There has been little research in children providing quantitative and comparative analyses of cardiorespiratory responses to S-HIIE and CE. Hence, we compared $\mathrm{VO}_{2}$, HR responses and exercise time spent above $95 \%$ peakVO 2 during S-HIIE and CE. These exercise modalities were matched for total duration of exercise ("isotime") to compare the aerobic system activation. Exercise intensity seems to be a key factor in training design and an intensity of at least $80 \%$ HRmax has been suggested to be required to obtain significant increase in aerobic fitness in children [3]. Thus, we were employed CE with intensities of at least $80 \%$ of MAV. In the present study, S-HIIE protocols were performed at speeds above MAV using work to rest ratios that were previously shown to improve MAV similarly to CE protocols [3, 4]. Up to date various matching methods, such as work [1], energy expenditure, or time to exhaustion [23, 30] have been used when comparing the physiological responses of continuous and intermittent exercise protocols. Nicolo et al. [20] underlined the influence of the overall effort and total 
duration of exercise when comparing continuous with intermittent exercise protocols. In the present study, the total exercise duration was similar between the different sessions, but the protocol was not designed to have the same mean intensity, or to be performed at the maximal sustainable intensity ("isoeffort” approach) across all exercise modalities.

\section{Effect of exercise modalities on maximal percentage of peakV $\mathrm{O}_{2}$ and peakHR reached}

Midgley and Mc Naughton [19] have suggested that the percentage of peak $\mathrm{VO}_{2}$ attained during an acute bout of exercise may be a factor determining the improvement of peak $\mathrm{VO}_{2}$. In the present study, the percentages of peakVO 2 and peakHR attained were significantly higher in CE than S-HIIE despite that the two protocols had similar total exercise duration. Our results are in accordance with those of Borel et al. [7] who showed significantly higher cardiorespiratory activation in response to continuous exercise when performed at $80 \%$ of MAV compared to intermittent exercise performed at $110 \%$ of $\mathrm{MAV}$. PeakVO 2 and peakHR responses in the present study were also similar to those reported by Zafeiridis et al. [30] where the adolescents had to run either continuously at $83 \%$ of MAV or to perform 30 -s runs at $110 \%$ MAV with 30 -s recovery at $50 \%$ of MAV until exhaustion. However, the above study showed that a long intermittent exercise consisting of $3 \mathrm{~min}$ runs at $95 \%$ of MAV with 3 min recovery at $35 \%$ of MAV activated the aerobic system to a greater extent than CE and S-HIIE [30]. Long interval intermittent exercise (LIE) at intensities close to $\mathrm{VO}_{2}$ max has been known to be optimal to activate the aerobic system [1]. However, LIE is less commonly used than S-HIIE in young children, and in contrast to adolescents its effects on aerobic system activation have not been investigated. Wakefield and Glaister [26] have suggested that work period duration longer than $25 \mathrm{~s}$ at intensities $>100 \%$ of MAV are needed to optimize time at peakVO $\mathrm{V}_{2}$. Hence, exercise work bouts of at least $30 \mathrm{~s}$ at 100 and $110 \%$ of MAV may be required to provide significant activation of the aerobic system. In young adults, Zafeiridis et al. [28] reported that activation of the aerobic system was also similar during a continuous exercise performed at $70 \%$ of cycling 
power corresponding to $\mathrm{VO}_{2 \max }$ and a short intermittent protocol with $30 \mathrm{~s}$ at $100 \%$ power corresponding to $\mathrm{VO}_{2 \max }$ with $30 \mathrm{~s}$ passive recovery $\left(84.6 \pm 1.1 \%\right.$ and $83 \pm 7.4 \%$ of $\mathrm{VO}_{2} \max$, respectively). Notably, the percentages of $\mathrm{VO}_{2}$ peak attained in Zafeiridis 'study [28] were similar to those observed in the present study using higher work-bout intensities $(120 \%$ and $130 \%$ of MAV) with shorter durations (10 and 20s).

\section{Effect of exercise modalities on time spent above $95 \%$ peak $\mathrm{VO}_{2}$}

Increase in $\mathrm{VO}_{2}$ max following training protocols has been suggested to depend on time spent at $\mathrm{VO}_{2} \max \left(\mathrm{tVO}_{2} \max \right)$ [19] and is greater when using exercise bouts with intensity ranging from 90 to $100 \%$ of $\mathrm{VO}_{2} \max$ [26]. The calculation of $\mathrm{tVO}_{2} \max$ depends on the variability in $\mathrm{VO}_{2}$ max. In the present study, the determination of the $\mathrm{VO}_{2} \mathrm{max}$ of the day was not made. However, to calculate in the most accurate way $\mathrm{tVO}_{2} \max$, the sum of times spent above $95 \%$ of the $\mathrm{VO}_{2} \max$ was used [10]. We found that children spent significantly longer time above 95\% of $\mathrm{VO}_{2}$ peak during CE85 protocol compared to S-HIIE protocols employing 10 and 20-s runs at speeds corresponding to 120 and $130 \%$ of MAV and to 5s all-out runs. Furthermore, CE performed at $80 \%$ of MAV was superior to both 5 and 10-sec HIIE running protocols to elicit longer exercise time above $95 \%$ of peakVO $\mathrm{V}_{2}$

As demonstrated in adults [12], HIIE performed at $90 \%$ of $\mathrm{VO}_{2}$ max taxed physiologically to the same manner than steady state exercise at $70 \%$ of $\mathrm{VO}_{2} \mathrm{max}$, but is influenced by the workto-rest duration ratio. Gosselin et al. [12] stated that HIIE may be used as an alternative approach to $\mathrm{CE}$, but with less time commitment. The total time spent at a high percentage of peakVO 2 during S-HIIE determines the adaptive gain of peakVO $\mathrm{VO}_{2}$ and power output at peakVO [21]. Seiler et al. [21] have reported interactions on physiological adaptations between intensity and work duration in HIIE, which must be taken into account when designing aerobic training protocols. To our knowledge, three studies have investigated tpeakVO 2 in children [15] and adolescents [29, 30] with exercise of different intensities. However direct comparison with 
Leclair' study [15] is difficult as the authors reported the time spent at $\mathrm{VO}_{2}$ peak as the time above $90 \% \mathrm{VO}_{2}$ peak. On the other hand, similarly to our study, they also reported a high interindividual variability for the time spent at high $\mathrm{VO}_{2}$ rates $(47.9 \pm 69.1 \mathrm{~s}$ and $34.2 \pm 34.5 \mathrm{~s}$ for $100 \%$ and $110 \%$ of MAP, respectively). In Zaferidis studies [29, 30], adolescents had also to run until exhaustion either continuously at $83 \%$ of MAV or using 30 s runs at $110 \%$ MAV. The time spent above $95 \%$ of $\mathrm{VO}_{2} \max$ was not significantly different between the two protocols (85 \pm 200 and $54 \pm 66 \mathrm{~s}$, respectively for CE and S-HIIE). Zafeiridis et al. [29, 30] concluded that $\mathrm{CE}$ of appropriate intensity and duration might be as effective as S-HIIE for taxing the aerobic system above $90 \%$ of VO2 max. In the present study, the duration of S-HIIE (10 or 20s) at 100 and $110 \%$ of MAV appeared insufficient to achieve a substantial tpeakVO 2 , compared to the 30-s runs in Zafeiridis studies [29, 30].

S-HIIE3 was associated with less tpeakVO $\mathrm{V}_{2}$ than $\mathrm{CE}$ and HIIE2. Such an observation may contribute to explain why some [27], but not all [18] failed to observe improved peakVO $\mathrm{V}_{2}$ in response to repeated sprint training. Hence, the potentially lower effect of repeated sprint exercise to elicit a high percentage of peakVO $\mathrm{V}_{2}$ in children may explain the lower peakVO improvement when this type of exercise is used for exercise training. Similarly, to S-HIIE 1 and 2 at 100 and $110 \%$ MAV, S-HIIE3 did not allow to spend a substantial amount of time above $95 \% \mathrm{VO}_{2}$ peak.

The longer time above $95 \%$ of $\mathrm{VO}_{2}$ peak during CE85 and CE80 protocols could be explained by differentially stroke volume responses and the contribution of the metabolic systems to energy production that depends on intensity and duration differences [8]. In a study with adults, Zafeiridis et al. [29] showed that under isoeffort conditions continuous and long-interval (3 min exercise bouts) protocols resulted to higher average cardiac output and stroke volume responses compared to 30 -sec exercise bouts with passive recovery. However, if the goal is to improve muscle $\mathrm{O} 2$-utilization potentials, all 3 protocols appeared equally effective. In the present study, 
exercise modalities were matched for total duration of exercise ("isotime") to compare the aerobic system activation. Further studies are needed to analyze the central and peripheral components of $\mathrm{VO}_{2}$ in children on isoeffort conditions. 


\section{Conclusion}

Our study has shown that in prepubertal children, CE performed at 80 and $85 \%$ of MAV activated the aerobic system to a greater extent compared to isotime HIIE protocols performed at $100-130 \%$ of MAV. However, S-HIIE protocols of total equal duration exercise bouts of either 10 or 20 -s at intensity above MAV accumulate similar exercise time above $95 \%$ of $\mathrm{VO}_{2}$ peak. Thus, these S-HIIE exercise modalities may be be used interchangeably to decrease the monotony of training. 


\section{References}

1. Astrand I, Astrand PO, Christensen EH, Hedman R. Intermittent muscular work. Acta Physiol Scand 1960; 48: 448-453

2. Baquet G, Berthoin S, Van Praagh E. Endurance training and aerobic fitness in young people. Sports Med 2003; 15: 1127-1145

3. Baquet G, Berthoin S, Dupont G, Blondel N, Fabre C, Van Praagh E. Effects of high intensity intermittent training on peak $\mathrm{VO}_{2}$ in prepubertal children. Int J Sports Med 2002; 23: 439-444

4. Berthoin S, Mantéca F, Gerbeaux M, Lensel-Corbeil G. Effect of a 12-week training programme on Maximal Aerobic Speed (MAS) and running time to exhaustion at $100 \%$ of MAS for students aged 14 to 17 years. J Sports Med Phys Fitness 1995; 35(4): 251-256

5. Billat $V$. Interval training for performance: a scientific and empirical practice. Special recommendations for middle- and long-distance running. Part I: aerobic interval training. Sports Med 2001; 31(1): 13-31

6. Billat $V$ and Koralsztein JP. Significance of the velocity at $\mathrm{VO}_{2} \mathrm{max}$ and time to exhaustion at this velocity. Sports Med 1996; 22: 90-108

7. Borel B, Leclair E, Thevenet D, Beghin L, Berthoin S, Fabre C. Correspondences between continuous and intermittent exercises intensities in healthy prepubescent children. Eur $\mathbf{J}$ Appl Physiol 2010; 108(5): 977-985

8. Buchheit $M$, Laursen $P B$. High-intensity interval training, solutions to the programming puzzle: Part I: cardiopulmonary emphasis. Sports Med 2013; 43: 313-338

9. Costigan SA, Eather N, Plotnikoff RC, Taaffe DR, Lubans DR. High-intensity interval training for improving health-related fitness in adolescents: a systematic review and meta-analysis. $\mathrm{Br}$ J Sports Med 2015; 49: 1253-1261

10. Dupont $G$, Blondel N, Berthoin $S$. Time spent at $\mathrm{VO}_{2}$ max: a methodological issue. Int J Sports Med 2003; 24(4): 291-297 
11. Gist NH, Fedewa MV, Dishman RK, Cureton KJ. Sprint interval training effects on aerobic capacity: a systematic review and meta-analysis. Sports Med 2014; 44: 269-279

12. Gosselin LE, Kozlowski KF, DeVinney-Boymel L, Hambridge C. Metabolic response of different high-intensity aerobic interval exercise protocols. J Strength Cond Res 2012; 26(10): $2866-2871$

13. Harriss DJ, Atkinson G. Ethical standards in sport and exercise science research: 2016 Update Int J Sports Med 2015; 36: 1121-1124

14. Hopkins WG. A scale of magnitudes for effect statistics. In: A New view of Statistics (2002) Available at http: //www.sportsci.org/resource/stats/effectmag.html. Accessed 15 April, 2015.

15. Leclair E, Mucci P, Borel B, Baquet G, Carter H, Berthoin S. Time to exhaustion and time spent at a high percentage of VO2max in severe intensity domain in children and adults. $\mathrm{J}$ Strength Cond Res 2011; 25(4): 1151-1158

16. Lohman TG. Advances in body composition assessment. Champaign, IL: Human Kinetics, 1992

17. McLaughlin JE, King GA, Howley ET, Bassett DR Jr, Ainsworth BE. Validation of the Cosmed $\mathrm{K} 4 \mathrm{~b}^{2}$ portable metabolic system. Int J Sports Med 2001; 22: 280-284

18. McManus, Armstrong N, Williams CA. Effect of training on the aerobic power and anaerobic performance of prepubertal girls. Acta Paediatr. 1997; 86:456-459.

19. Midgley $A W$, Mc Naughton LR. Time at or near $\mathrm{VO}_{2} \max$ during continuous and intermittent running. A review with special reference to considerations for the optimisation of training protocols to elicit the longest time at or near $\mathrm{VO}_{2} \max$. J Sports Med Phys Fitness 2006; 46(1): $1-14$

20. Nicolo A, Bazzucchi I, Haxhi J, Felici F, Sacchetti M. Comparing Continuous and Intermittent Exercise: An "Isoeffort" and "Isotime" Approach. PLoS ONE. 2014; 9(4): e94990. doi:10.1371 
21. Seiler $S$, Jøranson $K$, Olesen $B V$, Hetlelid $K J$. Adaptations to aerobic interval training: interactive effects of exercise intensity and total work duration. Scand J Med Sci Sports 2013; 23(1): $74-83$

22. Tanner JM. Growth at adolescence ( $2^{\text {nd }}$ Ed). Oxford, UK: Blackwell, 1962:325

23. Thévenet D, Tardieu-Berger $M$, Berthoin $S$, Prioux $J$. Influence of recovery mode (passive vs. active) on time spent at maximal oxygen uptake during an intermittent session in young and endurance-trained athletes. Eur J Appl Physiol 2007; 99(2): 133-142

24. Tolfrey K, Campbell IG, Batterham AM. Aerobic trainability of prepubertal boys and girls. Ped Exerc Sci 1998; 10: 248-263

25. Wakefield BR, Glaister M. Influence of work-interval intensity and duration on time spent at a high percentage of VO2max during intermittent supramaximal exercise. J Strength Cond Res 2009; 23(9): 2548-2554

26. Wenger HA, Bell GJ. The interactions of intensity, frequency and duration of exercise training in altering cardiorespiratory fitness. Sports Med 1986; 3(5): 346-356

27. Williams CA, Armstrong N, Powell J. Aerobic responses of prepubertal boys to two modes of training. Br J Sports Med. 2000; 34: 168-173.

28. Zafeiridis A, Kounoupis A, Dipla K, Kyparos A, Nikolaidis MG, Smilios I, Vrabas IS. Oxygen Delivery and Muscle Deoxygenation during Continuous, Long- and Short-Interval Exercise. Int J Sports Med 2015; 36(11): 872-880

29. Zafeiridis A, Rizos S, Sarivasiliou H, Kazias A, Dipla K, Vrabas IS. The extent of aerobic system activation during continuous and interval exercise protocols in young adolescents and men. Appl Physiol Nutr Metab 2011; 36(1): 128-136

30. Zafeiridis A, Sarivasiliou H, Dipla K, Vrabas IS. The effects of heavy continuous versus long and short intermittent aerobic exercise protocols on oxygen consumption, heart rate, and lactate responses in adolescents. Eur J Appl Physiol 2010; 110(1): 17-26 
TABLE 1 Details of short high-intensity intermittent exercise (S-HIIE) and continuous submaximal exercise (CE) sessions 31.

\begin{tabular}{|c|c|c|}
\hline & Sessions & Recovery and session duration \\
\hline $\begin{array}{l}\text { S-HIIE } 1 \\
\text { Exercises } \\
\text { 10/10s }\end{array}$ & $\begin{array}{l}1 \text { set }(10 * 10 \mathrm{~s}) \text { at } 100 \% \text { of MAV } \\
2 \text { sets }(10 * 10 \mathrm{~s}) \text { at } 110 \% \text { of MAV } \\
1 \text { set }(10 * 10 \mathrm{~s}) \text { at } 120 \% \text { of MAV } \\
1 \text { set }(10 * 10 \mathrm{~s}) \text { at } 130 \% \text { of MAV }\end{array}$ & $\begin{array}{l}\text { 10s between each repetition } \\
\text { 3' between each set } \\
\text { Session duration: } 27\end{array}$ \\
\hline $\begin{array}{l}\text { S-HIIE } 2 \\
\text { Exercises } \\
\text { 20/20s }\end{array}$ & $\begin{array}{l}1 \text { set }(5 * 20 \mathrm{~s}) \text { at } 100 \% \text { of MAV } \\
2 \text { sets }(5 * 20 \mathrm{~s}) \text { at } 110 \% \text { of MAV } \\
1 \text { set }(5 * 20 \mathrm{~s}) \text { at } 120 \% \text { of MAV } \\
1 \text { set }(5 * 20 \mathrm{~s}) \text { at } 130 \% \text { of MAV }\end{array}$ & $\begin{array}{l}\text { 20s between each repetition } \\
\text { 3' between each set } \\
\text { Session duration: } 27\end{array}$ \\
\hline $\begin{array}{l}\text { S-HIIE } 3 \\
\text { Exercises } \\
\text { 5/15s }\end{array}$ & $\begin{array}{c}3 \text { sets }(15 * 5 \text { s) of sprint or jumping with } 15 \text { s of recovery } \\
\text { between each repetition }\end{array}$ & $\begin{array}{l}\text { 15s between each repetition } \\
5 \text { ' between each set } \\
\text { Session duration: } 25\end{array}$ \\
\hline CE80 & 2 sets of $10^{\prime}$ at $80 \%$ of MAV & $\begin{array}{l}5 \text {, between each set } \\
\text { Session duration: } 25\end{array}$ \\
\hline CE85 & 2 sets of $10^{\prime}$ at $85 \%$ of MAV & $\begin{array}{l}5 \text { ' between each set } \\
\text { Session duration: } 25 \text {, }\end{array}$ \\
\hline
\end{tabular}




\begin{tabular}{|c|c|c|c|c|c|c|}
\hline Parameters & & $\begin{array}{l}\text { S-HIIE } 1(10 \mathrm{~s}) \\
5 \text { sets of } 10 \\
\text { Repetitions }\end{array}$ & $\begin{array}{c}\text { S-HIIE } 2(20 \mathrm{~s}) \\
5 \text { sets of } 5 \text { Repetitions }\end{array}$ & $\begin{array}{c}\text { S-HIIE } 3(5 \mathrm{~s}) \\
3 \text { sets of } 15 \text { repetitions }\end{array}$ & $\begin{array}{c}\text { CE80 } \\
(2 \text { sets of } 10 \mathrm{~min})\end{array}$ & $\begin{array}{c}\text { CE85 } \\
(2 \text { sets of } 10 \mathrm{~min})\end{array}$ \\
\hline 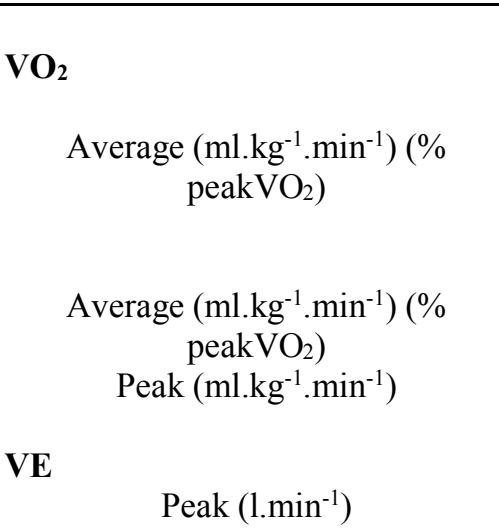 & $\begin{array}{c}1^{\text {st }} \text { set } \\
2^{\text {nd }} \text { set } \\
3^{\text {rd }} \text { set } \\
4^{\text {th }} \text { set } \\
5^{\text {th }} \text { set } \\
\text { Whole session }\end{array}$ & $\begin{array}{c}35.3 \pm 4.8(64.6 \pm 6.5) \\
40.0 \pm 5.3(73.3 \pm 7.4) \\
40.5 \pm 5.6(74.1 \pm 7.3) \\
43.5 \pm 6.3(79.6 \pm 8.6) \\
45.4 \pm 6.8(83.0 \pm 9.8) \\
\\
\mathbf{3 1 . 1} \pm \mathbf{4 . 1}(\mathbf{5 7 . 0} \pm \mathbf{5 . 9}) \\
\mathbf{5 6 . 5 8} \pm \mathbf{6 . 4 6} \\
\\
\mathbf{7 0 . 6 7} \pm \mathbf{1 0 . 3 9}\end{array}$ & $\begin{array}{c}35.3 \pm 5.5(64.5 \pm 7.0) \\
41.3 \pm 5.8(75.5 \pm 5.9) \\
42.3 \pm 5.5(77.3 \pm 5.7) \\
45.0 \pm 5.0(82.3 \pm 5.5) \\
47.0 \pm 6.0(85.9 \pm 6.5) \\
\\
\mathbf{3 2 . 7} \pm \mathbf{3 . 9}\left(\mathbf{5 9 . 8} \pm \mathbf{4 . 3} \mathbf{3}^{\circ \circ \circ)}\right. \\
\mathbf{5 9 . 8 7} \pm \mathbf{6 . 0 8} \\
\\
\mathbf{7 6 . 6 2} \pm \mathbf{8 . 7 4}^{\circ \circ \circ}\end{array}$ & $\begin{array}{c}38.1 \pm 5.3(69.9 \pm 8.3) \\
37.3 \pm 5.8(68.4 \pm 8.9) \\
36.8 \pm 6.1(67.5 \pm 10.2)\end{array}$ & $\begin{array}{c}40.5 \pm 5.3(72.9 \pm 6.9 * * *) \\
56.51 \pm 6.03 \\
68.21 \pm 8.43\end{array}$ & $\begin{array}{c}43.1 \pm 6.5(77.0 \pm 6.0 * * *) \\
56.51 \pm 6.03 \\
70.21 \pm 9.45^{\circ \circ}\end{array}$ \\
\hline $\begin{array}{l}\text { HR } \\
\text { Average (bpm) (\% HRmax) } \\
\text { Average (bpm) (\% HRmax) } \\
\text { Peak (bpm) }\end{array}$ & $\begin{array}{c}1^{\text {st }} \text { set } \\
2^{\text {nd }} \text { set } \\
3^{\text {rd }} \text { set } \\
4^{\text {th }} \text { set } \\
5^{\text {th }} \text { set } \\
\text { Whole session }\end{array}$ & $\begin{array}{c}169 \pm 9(78.6 \pm 5.0) \\
181 \pm 7(84.1 \pm 4.3) \\
182 \pm 8(84.6 \pm 4.5) \\
189 \pm 7(88.1 \pm 3.4) \\
195 \pm 8(90.8 \pm 3.0) \\
\\
\mathbf{1 6 1} \pm \mathbf{8}(\mathbf{7 5 . 2} \pm \mathbf{4 . 2}) \\
\mathbf{2 0 8} \pm \mathbf{8}\end{array}$ & $\begin{array}{c}171 \pm 9(79.7 \pm 5.0) \\
183 \pm 8(85.2 \pm 3.9) \\
186 \pm 9(86.4 \pm 4.2) \\
192 \pm 9(89.5 \pm 3.5) \\
198 \pm 8(92.1 \pm 3.2) \\
\\
\mathbf{1 6 5} \pm \mathbf{8}(\mathbf{7 6 . 6} \pm \mathbf{3 . 2}) \\
\mathbf{2 1 1} \pm 7^{\circ 00}\end{array}$ & $\begin{array}{c}183 \pm 9(85.3 \pm 3.9) \\
184 \pm 9(85.6 \pm 4.0) \\
185 \pm 10(86.3 \pm 4.3) \\
\\
\mathbf{1 6 1} \pm \mathbf{9}(\mathbf{7 4 . 9} \pm \mathbf{3 . 8}) \\
\mathbf{2 0 4} \pm \mathbf{8}\end{array}$ & $\begin{array}{c}189 \pm 10(88 \pm 3.7) \\
192 \pm 10(89.8 \pm 3.6) \\
\mathbf{1 7 9} \pm \mathbf{9}(\mathbf{8 3 . 5} \pm \mathbf{3 . 6} * * *) \\
\mathbf{2 1 0} \pm 7^{\circ}\end{array}$ & $\begin{array}{c}186 \pm 8(87.2 \pm 3.7 * * *) \\
211 \pm 7^{\circ 00}\end{array}$ \\
\hline t $_{95}$ peakVO 2 (s) (\% exercise time) & $\begin{array}{c}1^{\text {st }} \text { set } \\
2^{\text {nd }} \text { set } \\
3^{\text {rd }} \text { set } \\
4^{\text {th }} \text { set } \\
5^{\text {th }} \text { set } \\
\text { Whole session }\end{array}$ & $\begin{array}{c}8 \pm 14(4.3 \pm 7.5) \\
24 \pm 28(12.8 \pm 13.7) \\
24 \pm 25(12.7 \pm 13.4) \\
44 \pm 38(23.1 \pm 19.9) \\
69 \pm 51(36.3 \pm 26.8) \\
169 \pm 140(\mathbf{1 7 . 8} \pm \mathbf{1 4 . 8})\end{array}$ & $\begin{array}{c}8 \pm 16(4.0 \pm 8.2) \\
32 \pm 25(17.0 \pm 13.2) \\
42 \pm 31(21.9 \pm 16.5) \\
68 \pm 36(36.0 \pm 19.1) \\
87 \pm 41(45.6 \pm 21.5) \\
\mathbf{2 3 7} \pm \mathbf{1 1 9}(\mathbf{2 4 . 9} \pm \mathbf{1 2 . 5})^{\circ}\end{array}$ & $\begin{array}{l}32 \pm 45(10.8 \pm 15.0) \\
30 \pm 37(10.0 \pm 12.4) \\
37 \pm 47(12.4 \pm 15.8) \\
\\
\mathbf{9 9} \pm \mathbf{1 3 0}(\mathbf{1 1 . 1} \pm \mathbf{1 4 . 0})\end{array}$ & $\begin{array}{l}175 \pm 157(29.2 \pm 26.1) \\
226 \pm 176(37.6 \pm 29.3) \\
\mathbf{4 0 1} \pm \mathbf{3 1 4}(\mathbf{3 3 . 3} \pm \mathbf{2 6 . 2 *})\end{array}$ & $\begin{array}{r}282 \pm 183(47.1 \pm 30.5) \\
291 \pm 181(48.5 \pm 30.1) \\
\mathbf{5 7 3} \pm \mathbf{3 3 8}(\mathbf{4 7 . 8} \pm \mathbf{2 8 . 1 * *})\end{array}$ \\
\hline $\begin{array}{l}\text { Energy Expenditure (kcal) } \\
\text { Running distance (m) }\end{array}$ & & $\begin{array}{l}153 \pm 24.7^{\circ \circ \circ} \\
1851 \pm 172^{\circ \circ \circ}\end{array}$ & $\begin{array}{l}160.9 \pm 26.3^{\circ \circ \circ} \\
1851 \pm 172^{\circ \circ \circ}\end{array}$ & $\begin{array}{c}127.5 \pm 22.5 \\
741 \pm 69\end{array}$ & $\begin{array}{l}182.2 \pm 32.3 * * * \\
3118 \pm 290 * * *\end{array}$ & $\begin{array}{l}194.7 \pm 39.8^{* * * *} \\
3313 \pm 308^{* * *}\end{array}$ \\
\hline
\end{tabular}




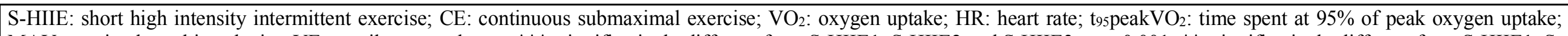

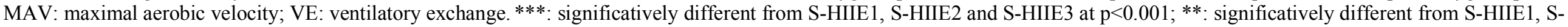

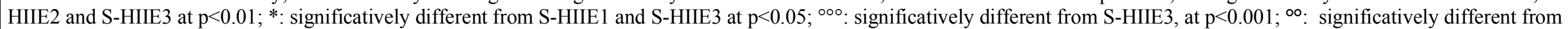

S-HIIE3, at $\mathrm{p}<0.01{ }^{\circ}{ }^{\circ}$ : significatively different from S-HIIE3, at $\mathrm{p}<0.05$. 
TABLE 3 Effect size and 95\% confidence intervals for Average oxygen uptake ( $\left.\mathrm{VO}_{2}\right)$, Average Heart Rate (HR) and time spent at $95 \%$ of peakVO between each session

\begin{tabular}{|c|c|c|c|c|c|c|}
\hline & Parameters & $\begin{array}{c}\text { S-HIIE } 1 \text { (10s) } \\
(100-130 \% \text { of MAV) }\end{array}$ & $\begin{array}{c}\text { S-HIIE } 2 \text { (20s) } \\
(100-130 \% \text { of MAV) }\end{array}$ & $\begin{array}{c}\text { S-HIIE 3 (5s) } \\
\text { (sprints and jumps) }\end{array}$ & CE80 (80\% of MAV) & CE85 (85\% of MAV) \\
\hline S-HIIE 1 (10s) & $\begin{array}{l}\text { Average } \mathrm{VO}_{2} \\
\text { Average } \mathrm{HR} \\
\text { t }_{95} \text { peakVO } \\
2\end{array}$ & & & & & \\
\hline \multirow[t]{3}{*}{ S-HIIE2 (20s) } & Average $\mathrm{VO}_{2}$ & $\begin{array}{c}\mathrm{ES}=0.56 \\
(95 \% \mathrm{CI}=-0.03,1.13)\end{array}$ & & & & \\
\hline & Average HR & $\begin{array}{c}\mathrm{ES}=0.38 \\
(95 \% \mathrm{CI}=-0.19,0.95)\end{array}$ & & & & \\
\hline & $\mathrm{t}_{95}$ peakVO${ }_{2}$ & $\begin{array}{c}\mathrm{ES}=0.49 \\
(95 \% \mathrm{CI}=-0.07,0.49)\end{array}$ & & & & \\
\hline \multirow[t]{3}{*}{ S-HIIE 3 (5s) } & Average $\mathrm{VO}_{2}$ & $\begin{aligned} \mathrm{ES} & =0.95 \\
(95 \% \mathrm{CI} & =0.33,1.53)\end{aligned}$ & $\begin{array}{c}\mathrm{ES}=1.61 \\
(95 \% \mathrm{CI}=0.96,2.27)\end{array}$ & & & \\
\hline & Average HR & $\begin{array}{c}\mathrm{ES}=0.03 \\
(95 \% \mathrm{CI}=-0.57,0.63)\end{array}$ & $\begin{array}{c}\mathrm{ES}=0.43 \\
(95 \% \mathrm{CI}=-0.12,0.98)\end{array}$ & & & \\
\hline & $\mathrm{t}_{95}$ peakVO${ }_{2}$ & $\begin{array}{c}\mathrm{ES}=0.48 \\
(95 \% \mathrm{CI}=-0.07,1.04)\end{array}$ & $\begin{aligned} \mathrm{ES} & =1.03 \\
(95 \% \mathrm{CI} & =0.45,1.61)\end{aligned}$ & & & \\
\hline \multirow{3}{*}{$\begin{array}{c}\text { CE80 } \\
(80 \% \text { of MAV) }\end{array}$} & & $\begin{aligned} \mathrm{ES} & =2.47 \\
(95 \% \mathrm{CI} & =1.72,3.22)\end{aligned}$ & $\begin{aligned} \mathrm{ES} & =2.34 \\
(95 \% \mathrm{CI} & =1.57,3.03)\end{aligned}$ & $\begin{array}{c}\mathrm{ES}=3.34 \\
(95 \% \mathrm{CI}=2.42,4.16)\end{array}$ & & \\
\hline & Average HR & $\begin{aligned} \mathrm{ES} & =2.08 \\
(95 \% \mathrm{CI} & =1.30,2.87)\end{aligned}$ & $\begin{array}{c}\mathrm{ES}=1.99 \\
(95 \% \mathrm{CI}=1.27,2.71)\end{array}$ & $\begin{aligned} \mathrm{ES} & =2.19 \\
(95 \% \mathrm{CI} & =1.46,2.53)\end{aligned}$ & & \\
\hline & $\mathrm{t}_{95}$ peakVO${ }_{2}$ & $\begin{aligned} \mathrm{ES} & =0.72 \\
(95 \% \mathrm{CI} & =0.12,1.31)\end{aligned}$ & $\begin{array}{c}\mathrm{ES}=0.41 \\
(95 \% \mathrm{CI}=-0.16,0.99)\end{array}$ & $\begin{aligned} \mathrm{ES} & =1.07 \\
(95 \% \mathrm{CI} & =0.46,1.67)\end{aligned}$ & & \\
\hline \multirow{3}{*}{$\begin{array}{c}\text { CE85 } \\
\text { (85\% of MAV) }\end{array}$} & Average $\mathrm{VO}_{2}$ & $\begin{array}{c}\mathrm{ES}=3.38 \\
(95 \% \mathrm{CI}=2.35,4.27)\end{array}$ & $\begin{aligned} \mathrm{ES} & =3.46 \\
(95 \% \mathrm{CI} & =2.43,3.47)\end{aligned}$ & $\begin{array}{c}\mathrm{ES}=4.24 \\
(95 \% \mathrm{CI}=3.05,4.25)\end{array}$ & $\begin{array}{c}\mathrm{ES}=0.7 \\
(95 \% \mathrm{CI}=-0.01,1.36)\end{array}$ & \\
\hline & Average HR & $\begin{aligned} \mathrm{ES} & =2.87 \\
(95 \% \mathrm{CI} & =1.76,3.92)\end{aligned}$ & $\begin{aligned} \mathrm{ES} & =3.10 \\
(95 \% \mathrm{CI} & =2.02,4.18)\end{aligned}$ & $\begin{aligned} \mathrm{ES} & =3.07 \\
(95 \% \mathrm{CI} & =2.03,4.19)\end{aligned}$ & $\begin{aligned} \mathrm{ES} & =0.98 \\
(95 \% \mathrm{CI} & =0.16,1.80)\end{aligned}$ & \\
\hline & $\mathrm{t}_{95}$ peakVO${ }_{2}$ & $\begin{aligned} \mathrm{ES} & =1.41 \\
(95 \% \mathrm{CI} & =0.70,2.12)\end{aligned}$ & $\begin{aligned} \mathrm{ES} & =1.15 \\
(95 \% \mathrm{CI} & =0.47,1.83)\end{aligned}$ & $\begin{aligned} \mathrm{ES} & =1.78 \\
(95 \% \mathrm{CI} & =1.04,2.53)\end{aligned}$ & $\begin{array}{c}\mathrm{ES}=0.50 \\
(95 \% \mathrm{CI}=-0.16,1.17)\end{array}$ & \\
\hline
\end{tabular}

